\title{
THE CORRELATION BETWEEN PERCENT LIVER WEIGHT (PLW) AND PERCENT FAT CELLS (PFC) OF LIVER IN HFD-STZ INDUCED DIABETIC RATS IN COMPARISON WITH INSULIN, METFORMIN AND COMBINATION TREATED DIABETIC RATS.
}

1. MBBS, M.Phil Anatomy Associate Professor Department of Anatomy

Dow International Medical College DUHS.

2. MBBS, M.Phil Anatomy Assistant Professor Department of Anatomy

Dow International Medical College DUHS.

3. MS Management Science, MBA (Human Resource

Management)

Assistant Professor

Department of Management

Sciences

DHA Suffa University.

4. MBBS, M.Phil Anatomy

Assistant Professor Department of Anatomy

Dow International Medical College, DUHS.

5. MBBS, M.Phil Anatomy

Assistant Professor Department of Anatomy

Karachi Institute of Medical

Sciences, $\mathrm{CMH}$ Malir.

Correspondence Address:

Dr. Sahar Mubeen

Department of Anatomy

Dow International Medical College,

DUHS.

sahar.mubeen@duhs.edu.pk

Article received on:

18/10/2018

Accepted for publication:

28/05/2019

Received after proof reading:

$31 / 07 / 2019$

\begin{abstract}
Sahar Mubeen', Mahrukh Kamran², Hina Mubeen ${ }^{3}$, Rabia Rehan ${ }^{4}$, Iffat Raza ${ }^{5}$
ABSTRACT... Background: The study was designed to evaluate short term effects of commonly used antidiabetic drugs on liver. The objective of the study is to observe and analyze the correlation between percent liver weight and percent liver fat cells in control rats and diabetic, insulin, metformin and insulin-metformin combination treated high fat diet (HFD) / Streptozotocin (STZ) induced diabetic albino rats. Study Design: Experimental comparative study. Setting: Institute of Bio Medical Sciences (IBMS), Dow University of Health Sciences (DUHS), Ojha Campus, Karachi. Period: December 2014 to May 2015. Materials and Methods: The experimental study was conducted on 50 albino wistar rats. 10 rats served as control rats while rest of the rats were experimentally induced for diabetes type 2 and were then randomized into 5 groups. One group was treated with insulin, one with metformin, and the one group with insulin-metformin combination for 4 weeks. All the treated groups were compared with untreated and control group. At the end of experiment, all the rats were sacrificed and livers were isolated and weighed. Percent liver weight calculated. Liver cut sections were processed and stained to analyze the correlation in percent fat cells in liver percent liver weight and in each treated and untreated diabetic groups, then the results were compared with control rats. Results: Data is analyzed by using SPSS Version 22. Pearson correlation was used to identify correlation between the percent liver weight and percent fat cells in liver of control, treated and untreated diabetic groups. Significant and positive correlation ( $p$-value $<0.01)$ in insulin treated group of diabetic rats was observed indicating that insulin has a role in causing fatty liver. Conclusion: Insulin treated diabetic group shows a significant positive correlation between percent fat cells of liver and percent liver weight.
\end{abstract}

Key words: $\quad$ Percent Liver Weight, Percent Fat Cells, Type 2 Diabetes, Non-alcoholic Fatty Liver, Hepatic Steatosis.

Article Citation: Mubeen S, Kamran M, Mubeen H, Rehan R, Raza I. The correlation between percent liver weight (PLW) and percent fat cells (PFC) of liver in HFD-STZ induced diabetic rats in comparison with insulin, metformin and combination treated diabetic rats. Professional Med J 2019; 26(8):12081212. DOI: $10.29309 / T P M J / 2019.26 .08 .227$

\section{INTRODUCTION}

We fortunately or unfortunately are living in modernized era where unhealthy dietary habits and physical inactivity can be considered as a keystone for all diseases. Use of high fat food and lack of exercise give birth to obesity leading to resistance to insulin (IR) and ending up with a lot more diseases. Fatty liver disease in diabetics remains unnoticed because of its silent course. There is strong association of IR with diabetes type 2 (DM2) and fatty liver disease. DM2/IR are well known chronic form of metabolic disorders due to decline in insulin action leading to increased circulating levels of blood glucose. ${ }^{1-3}$
With each passing day, prevalence of DM2 is increasing in our community as well as in the world. Approximately $1.3 \%$ population of the world is diabetic. ${ }^{4,5}$ According to IDF Diabetes Atlas, it was expected that in 2017 there are 451 million (age 18-99 years) people with diabetes worldwide. These figures were expected to increase to 693 million) by $2045 .^{6}$

Physical inactivity, fatty diet and diabetes are closely associated with nonalcoholic fatty liver disease (NAFLD). NAFLD is a fatty infiltration of liver cells involving sequelae of reversible steatosis, lobular steatohepatitis, hepatocytes ballooning to 
irreversible perisinusoidal fibrosis and liver failure. ${ }^{7}$ Hepatic Steatosis (HS) is a morphological pattern of liver injury that replaces healthy liver tissue Steatohepatitis develops in about $78 \%$ diabetic patients ${ }^{8}$ while the ultrasonograhic examination of liver in many diabetic patients demonstrate fat in liver. ${ }^{9}$ It has been focus of research because of is silent course in DM2 patients. ${ }^{10,11}$

Whether it is DM2 and NAFLD, Insulin resistance $\mathrm{IR}$ is considered as the main culprit. The resistance once developed leads to hyperglycemia and hyperinsulinemia, which stimulates lipid-accumulating processes and impairs fat metabolism in the liver. Free fatty acid (FFA) delivery to liver from the adipose tissue storage sites is increased due to continuous lipolysis. These changes result in HS which may induce Hepatic Insulin Resistance (HIR) and further aggravate the altered metabolic state of whole body which shows that there is a strong association between HS and IR. The whole body sensitivity to insulin decreases and at the same time fat accumulation in liver increases. ${ }^{7,12}$

Research on diabetes is still in search of the answers for complete treatment of diabetes. Therefore, anti-diabetic medicines are on and off evaluated for their effectiveness in controlling symptoms of the disease and minimizing side effects of the drugs. The most commonly advised drugs in diabetics are insulin and metformin. Insulin and metformin when used as a monotherapy seems to be less effective than insulin-metformin combination. The combination balances blood liver enzymes and keep blood glucose levels in normal range. ${ }^{13}$ On other hand, insulin when used as monotherapy is harmful to liver because of its lipid metabolism (lipogenic effect) while metformin seems to have good results in fatty liver disease and diabetes. ${ }^{14,15}$

Keeping in view that insulin and metformin are most commonly prescribed medicines in diabetes, the current study was designed to evaluate the correlation between percent liver weight (PLW) and percent fat cells (PFC) in liver in HFD/STZ-induced diabetic models (treated and non-treated). Its also logical that in DM2 patients with uncontrolled blood glucose levels, monotherapy either with insulin and metformin is not desirable rather a combination therapy is more beneficial. The present study revealed the beneficial therapeutic results according to which the metformin and combination therapy (insulin and metformin) is more effective in fatty liver diseases. A significant positive correlation between PLW and PFCs was observed in Insulin treated rats which indicates insulin itself contributes to fat in liver.

\section{METHODOLOGY}

\section{Study Design}

Experimental comparative study.

\section{Sampling Method}

Random.

\section{Sample Size}

Albino wistar rats $(n=50)$ weighing $160 \pm 20$ g.

10 rats were housed in a single clear sided plastic cage. All rats were kept at room temperature and were given balanced diet and water ad libitum, before any dietary manipulation. Body weight of all rats were noted on a digital scale at the beginning of the experiment and weekly until sacrificed. Experimental induction of DM2 was done with a combination of high fat diet (HFD) and a single I.P injection of STZ. ${ }^{8,13}$ Experimentally (HFD/ STZ) induced rats were randomized into 4 groups:

1. Group A/ control Group $(n=10)$.

2. Group $E /$ Diabetic rats $(n=10)$.

3. Group B / Diabetic rats treated with insulin $(n=10)$.

4. Group C/ Diabetic rats treated with metformin $(n=10)$.

5. Group D/Diabetic rats treated with insulin metformin combination $(n=10)$.

Group B was given Insulin (3U/kg/day), Group C was given metformin $(200 \mathrm{mg} / \mathrm{kg} / \text { day })^{16,17}$ and group $D$ was given Insulin-Metformin combination. After 4 weeks of treatment, rats were sacrificed and liver was carefully dissected out. The weight of the liver was noted on Sartorius balance. The 
percent weight of the liver was obtained by the formula: weight of liver/body weight of rat $x 100$. Liver was sectioned and placed in cassettes which were then immersed in $10 \%$ buffered formalin for 24-48hrs. Tissue was then stained with Hematoxylin and eosin stain and special stains to study the tissue from each group under light microscope. Each slide was examined by a single pathologist with hematoxylin and eosin sections for general hepatic morphology and Perodic-Acid Schiff (PAS) for fatty changes. Liver Steatosis was graded according to Brunt Score. ${ }^{18}$

\section{Statistical Analysis}

The collected data is analyzed by using SPSS version 22.0. To analyze the direction and strength of the relationship between percent liver weight and percent liver cells, Pearson correlation is used for all the five experimental groups of rats.

\section{RESULTS}

There were 10 rat specimens in each group. Table-I shows mean values of the variables. As per Table II, the results indicate strong positive correlation between percent liver weight and percent liver cells for Group B $(r=0.841)$. The correlation score was found to be statistically significant ( $p$-value $<0.01$ ). For Group $A$ and $\mathrm{C}$, there is a weak negative correlation and for Group $E$ moderate negative correlation $(r=$
0.484) has been observed. However, for all these groups $A, C$ and $E$, the correlation is statistically non-significant ( $p$-value $>0.01)$. There is a weak positive correlation between percent liver weight and percent fat cells for Group D nevertheless the correlation is statistically non-significant ( $p$-value $>$ 0.01). In general, the overall correlation indicates that only in case of insulin treated rats i.e. Group B, the percent fat cells in liver increases with increase in percent liver weight.

\section{DISCUSSION}

We have entered into an era of modernization in which our lives have become more comfortable and dependent on the machines. Other side of the picture shows more stress, unhealthy eating and physical inactivity. All these ill-habits have sown seeds for stress-related diseases like cardiovascular diseases, diabetes, fatty livers and many more. Out of many organs of the human body, liver is related to significant mortality and morbidity in diabetics. The current study focuses on analyzing the correlation between percent liver weight and percent fat cells the diabetic rat group treated with anti-diabetic medicines (insulin, metformin and insulin-metformin combination) and non-diabetic rat group. Diabetic patients have increased levels of liver enzymes, blood triglycerides and hepatic steatosis..$^{2,14}$

\begin{tabular}{|l|c|c|}
\multicolumn{1}{c|}{$\begin{array}{c}\text { GROUPS } \\
(\mathbf{n = 5 0 )}\end{array}$} & $\begin{array}{c}\text { PLW } \\
\text { MEAN } \mathbf{n} \text { SD }\end{array}$ & $\begin{array}{c}\text { PFC } \\
\text { MEAN } \pm \text { SD }\end{array}$ \\
\hline GROUP A (control) & $2.601 \pm 0.398$ & $6.215 \pm 8.509$ \\
\hline GROUP B (insulin treated) & $4.073 \pm 0.705$ & $19.977 \pm 16.402$ \\
\hline GROUP C (metformin treated) & $3.519 \pm 0.344$ & $11.567 \pm 19.439$ \\
\hline GROUP D (insulin-metformin treated) & $3.543 \pm 0.480$ & $2.674 \pm 2.518$ \\
\hline GROUP E (untreated diabetic) & $5.427 \pm 0.501$ & $33.289 \pm 7.531$ \\
\hline
\end{tabular}

Table-I. Mean values of percent liver weight (PLW) and percent fat cells (PFC) in all experimental groups

\begin{tabular}{|l|c|c|}
\multicolumn{1}{c|}{$\begin{array}{c}\text { Groups } \\
(\mathbf{n = 5 0 )}\end{array}$} & Pearson Correlation & P-Value \\
\hline GROUP A (control) & -0.197 & 0.586 \\
\hline GROUP B (insulin treated) & 0.841 & $0.002^{*}$ \\
\hline GROUP C (metformin treated) & -0.256 & 0.474 \\
\hline GROUP D (insulin-metformin treated) & 0.388 & 0.268 \\
\hline GROUP E (untreated diabetic) & -0.484 & 0.156 \\
\hline
\end{tabular}

Table-II. The correlation between percent liver weight (PLW) and percent fat cells (PFC) in liver of HFD-STZ induced diabetic rats in comparison with insulin, metformin and combination treated diabetic rats ${ }^{*} p$ value is significant 0.01 
After treatment phase, the livers were isolated and their PLW calculated. Moderate negative correlation has been observed in untreated diabetic rats. It might be because of decreased peripheral lipogenesis leading to increase in free fatty acids in liver when insulin is deficient. On the other hand, lipogenic pathways are activated in liver causing enlarged and fatty liver. ${ }^{19}$ The present observations are consistent with current study. ${ }^{20}$

Metformin, a well-known effective therapeutic agent as besides being an insulin sensitizer, it also reduces blood triglyceride levels and

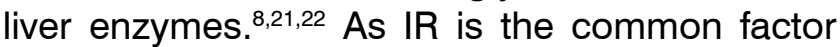
underlying DM2 and fatty liver disease, Metformin has promising role as being an insulin-sensitizer. ${ }^{17}$ It works by decreasing hyperinsulinemia and also by inhibiting lipogenic enzymes which decreases hepatomegaly and consequently HIR and HS. ${ }^{23,24}$ In the present study, a weak negative correlation between PLW and PFCs is observed in metformin treated rats as the treatment reduced body weight, liver weight and fat cells in liver. The results are in agreement with previous studies conducted by Lingvay I et al. 2007 and Lin HZ et al. 2000.

Insulin increases serum triglycerides and might be dangerous to liver. ${ }^{8}$ In our study, rats given insulin showed reduced blood glucose levels, PLW and steatosis. A significant positive correlation between PLW and PFCs was noticed in insulin is seen suggesting that insulin is lipogenic. On the other hand, the rats treated with a combination of both insulin and metformin showed a weak negative correlation PLW and PFCs which suggests that insulin metformin combination is effective for diabetic patients as it improves liver steatosis and its triggering factors.

\section{CONCLUSION}

Insulin treated group shows a positive correlation between percent fat cells in liver and percent liver weight.

\section{CONFLICT OF INTEREST}

I declare that there is no conflict of interest. Copyright@ 28 May, 2019.

\section{REFERENCES}

1. Srinivasan K, Viswanad B, Asrat L, Kaul C, Ramarao $P$. Combination of high-fat diet-fed and low-dose streptozotocin-treated rat: A model for type 2 diabetes and pharmacological screening. Pharmacological research. 2005; 52(4):313-20.

2. Association AD. Diagnosis and classification of diabetes mellitus. Diabetes care. 2014;37(Supplement 1):S81-S90.

3. Borghi C, Ventura F. Decrease mortality in type II diabetes mellitus: Glycemic and renal function control. Journal of Cardiovascular Medicine. 2018; 19:e13-e5.

4. Arul B, Kothai R, Christina A. Hypoglycemic activity of casearia esculenta roxb. in normal and diabetic albino rats. Iranian Journal of Pharmaceutical Research. 2010:47-51.

5. de Sá Borges AP, Guidoni CM, Ferreira LD, de Freitas O, Pereira LRL. The pharmaceutical care of patients with type 2 diabetes mellitus. Pharmacy world \& science. 2010; 32(6):730-6.

6. Cho N, Shaw J, Karuranga S, Huang Y, da Rocha Fernandes J, Ohlrogge A, et al. IDF Diabetes Atlas: Global estimates of diabetes prevalence for 2017 and projections for 2045. Diabetes research and clinical practice. 2018; 138:271-81.

7. Birkenfeld AL, Shulman GI. Nonalcoholic fatty liver disease, hepatic insulin resistance, and type 2 diabetes. Hepatology. 2014; 59(2):713-23.

8. Lingvay I, Raskin P, Szczepaniak LS. Effect of insulinmetformin combination on hepatic steatosis in patients with type 2 diabetes. Journal of diabetes and its complications. 2007; $21(3): 137-42$.

9. Bugianesi E, Gastaldelli A, Vanni E, Gambino R, Cassader $M$, Baldi $S$, et al. Insulin resistance in non-diabetic patients with non-alcoholic fatty liver disease: Sites and mechanisms. Diabetologia. 2005; 48(4):634-42.

10. Sorrentino P, Tarantino G, Conca P, Perrella A, Terracciano $\mathrm{ML}$, Vecchione $\mathrm{R}$, et al. Silent non-alcoholic fatty liver disease-a clinical-histological study. Journal of hepatology. 2004; 41(5):751-7.

11. Bedossa P. Pathology of non $\square$ alcoholic fatty liver disease. Liver International. 2017; 37:85-9.

12. Giorda C, Forlani G, Manti R, Mazzella N, De Cosmo S, Rossi $\mathrm{MC}$, et al. Occurrence over time and regression of nonalcoholic fatty liver disease in type 2 diabetes. Diabetes/ metabolism research and reviews. 2017; 33(4):e2878. 
13. Silvares RR, Pereira ENGdS, Flores EEI, Estato V, Reis PA, Silva IJd, et al. Combined therapy with metformin and insulin attenuates systemic and hepatic alterations in a model of high $\square$ fat $\operatorname{diet} \square /$ streptozotocin $\square$ induced diabetes. International journal of experimental pathology. 2016; 97(3):266-77.

14. Abeeleh MA, Ismail ZB, Alzaben KR, Abu-Halaweh SA, Al-Essa MK, Abuabeeleh J, et al. Induction of diabetes mellitus in rats using intraperitoneal streptozotocin: A comparison between 2 strains of rats. Eur J Sci Res. 2009; 32(3):398-402.

15. Mubeen S, Amjad Z, Memon FM, Ashraf SU. The Short-term effects of insulin, metformin and insulinmetformin combination on the liver morphology in high fat diet/streptozotocin induced diabetic albino rats. Journal of the College of Physicians and Surgeons-Pakistan: JCPSP. 2016; 26(12):962-6.

16. Imhof A, Kratzer W, Boehm B, Meitinger K, Trischler G, Steinbach $G$, et al. Prevalence of non-alcoholic fatty liver and characteristics in overweight adolescents in the general population. European journal of epidemiology. 2007; 22(12):889-97.

17. Siebler J, Galle PR. Treatment of nonalcoholic fatty liver disease. World Journal of Gastroenterology: WJG. 2006; 12(14):2161.

18. Brunt EM, editor. Nonalcoholic steatohepatitis. Seminars in liver disease; 2004: Copyright $(2004$ by Thieme Medical Publishers, Inc., 333 Seventh Avenue, New York, NY 10001, USA.
19. Seppälä-Lindroos A, Vehkavaara S, Häkkinen A-M, Goto T, Westerbacka J, Sovijärvi A, et al. Fat accumulation in the liver is associated with defects in insulin suppression of glucose production and serum free fatty acids independent of obesity in normal men. The Journal of Clinical Endocrinology \& Metabolism. 2002; 87(7):3023-8.

20. Zafar M, Naqvi SN-u-H. Effects of STZ-Induced diabetes on the relative weights of kidney, liver and pancreas in albino rats: A comparative study. International Journal of Morphology. 2010; 28(1).

21. Song S, Andrikopoulos S, Filippis C, Thorburn AW, Khan D, Proietto J. Mechanism of fat-induced hepatic gluconeogenesis: Effect of metformin. American Journal of Physiology-Endocrinology And Metabolism. 2001; 281 (2):E275-E82.

22. Zhou G, Myers R, Li Y, Chen Y, Shen X, Fenyk-Melody $\mathrm{J}$, et al. Role of AMP-activated protein kinase in mechanism of metformin action. The Journal of clinical investigation. 2001; 108(8):1167-74.

23. Nair S, Diehl A, Wiseman M, Farr G, Perrillo R. Metformin in the treatment of non $\square$ alcoholic steatohepatitis: A pilot open label trial. Alimentary pharmacology \& therapeutics. 2004; 20(1):23-8.

24. Lin HZ, Yang SQ, Chuckaree C, Kuhajda F, Ronnet G, Diehl AM. Metformin reverses fatty liver disease in obese, leptin-deficient mice. Nature medicine. 2000; 6(9):998-1003.

\begin{tabular}{|c|c|c|c|}
\hline \multicolumn{4}{|c|}{ AUTHORSHIP AND CONTRIBUTION DECLARATION } \\
\hline Sr. \# & Author-s Full Name & Contribution to the paper & Author $=\mathbf{s}$ Signature \\
\hline 1 & Sahar Mubeen & Manuscript idea and writing. & \\
\hline 2 & Mahrukh Kamran & $\begin{array}{l}\text { Writing and proof reading } \\
\text { Manuscript. }\end{array}$ & Manation ke \\
\hline 3 & Hina Mubeen & Statistical analysis. & Hing \\
\hline 4 & Rabia Rehan & $\begin{array}{l}\text { Writing and proof reading } \\
\text { manuscript. }\end{array}$ & Rabia \\
\hline 5 & Iffat Raza & $\begin{array}{l}\text { Writing and proof reading } \\
\text { manuscript. }\end{array}$ & \\
\hline
\end{tabular}

